\title{
Gama Işımasının Kolza Takviyeli Polipropilen Kompozit Malzemenin Mekanik Özellikleri Üzerindeki Etkisi
}

\author{
Akar Doğan ${ }^{1 *}$, Yılmaz Kısmet ${ }^{2}$ \\ ${ }^{1}$ Munzur Üniversitesi, Nadir Toprak Elementleri Uygulama ve Araştırma Merkezi, Tunceli, Türkiye \\ ${ }^{2}$ Munzur Üniversitesi, Mühendislik Fakültesi, Makine Mühendisliği, Tunceli, Türkiye \\ *akardogan@munzur.edu.tr (D), ykismet@munzur.edu.tr (D) \\ Makale gönderme tarihi:16.09.2021, Makale kabul tarihi: 01.11.2021
}

\begin{abstract}
$\ddot{O} \mathbf{z}$
$\mathrm{Bu}$ araştırmada, kurutulmuş ve toz haline getirilmiş kolza bitkisi takviyeli polipropilen matrisli kompozit malzemenin, çekme, üç nokta eğilme ve Izod darbe mukavemetleri gibi mekanik özellikleri deneysel olarak incelenmiştir. Öncelikle matris malzemesi polipropilen olan ve ağırlıça $\% 5, \% 10$ ve $\% 20$ oranında kolza içeren numuneler ekstrüzyon ve plastik enjeksiyon teknikleri kullanılarak üretilmiştir. Üretilen malzemelerin bir kısmı gama 1şımasına tabi tutularak matris ve dolgu malzemesi arasındaki fiziksel bağlanma mekanizması güçlendirilmeye çalışılmıştır. Bu doğrultuda 1şıma öncesi ve ışıma sonrası numunelerin mekanik özelliklerindeki değişimler araştırıldı. Yapılan testler sonucunda, çekme ve Izod darbe mukavemetleri, takviye olarak kullanılan kolza miktarının artması ile düştüğü, eğilme mukavemetinin ise arttığı gözlenmiştir. Gama ışımasına maruz bırakılan numunelerin çekme, eğilme ve Izod darbe mukavemetlerinde gama 1şımasına maruz bırakılmamış numunelere göre artış meydana geldiği tespit edildi.
\end{abstract}

Anahtar Kelimeler: Gama 1şıması, kolza, mekanik özellikler, polipropilen

\section{Effect of Gamma Radiation on Mechanical Properties of Rape Reinforced Polypropylene Composite Material}

\begin{abstract}
In this research, the mechanical properties of the dried and powdered rape reinforced polypropylene matrix composite material such as tensile, three-point bending and Izod impact strengths were experimentally investigated. Initially, samples whose matrix material was polypropylene and containing $5 \%, 10 \%$ and $20 \%$ by weight rape were produced using extrusion and plastic injection techniques. Some of the samples produced were exposed to gamma irradiation to strengthen the physical bonding mechanism between the matrix and the filling material. In this direction, the changes in the mechanical properties of the samples before and after gamma irradiation were investigated. As a result of the tests, it was observed that the tensile and Izod impact strengths decreased with the increase in the amount of rape used as reinforcement, while the bending strength increased slightly. It was determined that the tensile, bending and Izod impact strengths of the samples exposed to gamma irradiation increased compared to the samples that were not exposed to gamma irradiation.
\end{abstract}

Keywords: Gamma radiation, rape, mechanical properties, polypropylene

\section{GİRIŞ}

Kompozit malzemeler sahip oldukları yüksek mukavemet ağırlık oranları gibi özellikler sayesinde günümüzde birçok uygulamada siklıkla kullanılmaktadır (Dogan ve Arman, 2018; Madenci ve Ozutok, 2020; Madenci ve ark., 2020). Polimer kompozitlerde takviye elemanı sentetik ve doğal lifler olarak kategorize edilebilir. Sentetik liflerden bazıları cam, karbon, bazalt ve Kevlar'dır (Kismet ve Dogan, 2021). Sentetik lifler sahip oldukları iyi mekanik özellikler nedeniyle on yıllardır sıklıkla kullanılmaktadır (Özkılıç ve ark., 2020; Madenci ve ark., 2020). Bununla birlikte, kompozit malzemeye duyulan ihtiyacın artması ile özellikle karbon ve cam elyaf gibi sentetik liflerin yüksek maliyetleri nedeniyle günümüzde pek çok bilim insanı ve araştırmacı, çevreye olan zararı azaltmak ve maliyetleri düşürmek için cam ve karbon elyaf gibi sentetik takviye elemanlarının yerine, doğal liflerin 
kullanımını araştırarak hem ucuz hemde çevre dostu ürünler yapmaya büyük ilgi göstermişlerdir. Ayrıca, sürdürülebilir olmayan ürünleri sürdürülebilir ürünlerle değiştirilmesi büyük bir ihtiyaç ve gerekliliktir (Jariwala ve Jain, 2019; Singh ve ark., 2020; Kandas ve Özdemir, 2021). Bu sebeplerden dolay1 doğal elyaf takviyeli polimer kompozit malzemeler üzerine birçok araştırma gerçekleştirilmiştir. Muz lifi (Kenned ve ark., 2020), hindistan cevizi lifi (Widnyanave ark, 2020), bambu (Aruchamy ve ark., 2020), jüt (Ovalı ve Sancak, 2020) ve keten (Wang ve ark., 2020) en çok tercih edilen doğal lifler olarak sıralanabilir.

Doğal liflerin en büyük dezavantajı, polimer malzemeler ile bir araya geldiğinde düşük ara yüzey yapışmalarına sahip olmalarıdır. Araştırmacılar, bu ara yüzey yapışma mukavemetini arttırmak için çeşitli yöntemler denemiştir. Bu yöntemler fiziksel ve kimyasal olmak üzere ikiye ayrilabilir. Bununla birlikte fiziksel yöntemler pahalı oldukları için kimyasal yöntemler daha sik kullanılmaktadır (Vigneshwaran ve ark., 2020). Bu kimyasal yöntemlerin en çok kullanılanları ise alkali (Fiore ve ark., 2015; Alothman ve ark., 2020), Silan (Girones ve ark., 2007; Agrebi ve ark., 2020) ve asetilasyon (Simimol ve ark., 2020; Zaman ve ark., 2021) iyileştirilmesidir. Fiziksel iyileştirme yöntemlerine ise yüzey enerjisini arttıran ve doğal liflerin yüzeyini oksitleyen ve dolayısıyla hidrofilik lifler ile hidrofobik matris arasındaki uyumluluğu iyileştiren Korona yöntemi (Sreekala ve ark., 2000) ile zayıf bir şekilde bağlanmış yüzey katmanlarını kaldırarak ve yeni fonksiyonel gruplar oluşturarak liflerin yüzey özelliklerini değiştirmek için kullanılan plazma yöntemi (Koohestani ve ark., 2018) örnek olarak gösterilebilir.

$\mathrm{Bu}$ çalışmada ise literatürde yeteri kadar araştırılmamış olan kolza bitkisinin önemli bir ticari termoplastik olan polipropilende (PP) takviye elemanı olarak kullanılması incelenmiştir. Kurutulmuş ve toz haline getirilmiş kolza bitkisi ile güçlendirilmiş polipropilen kompozit numunelerin mekanik özellikleri incelenmiş ve ağırlıkça farklı oranlarda kolza takviyesi ile bu polipropilen numunelerinin çekme, üç nokta eğilme ve izod darbe mukavemetlerinde ki değişimler grafiklerle verilerek tartışılmıştır. Ayrıca, bu malzemeler gama 1şınına maruz bırakılarak, 1şımanın matris ve takviye elemanı üzerindeki etkileride incelenmiştir. Yapılan testler sonucunda gama ışıması ile ağırlıkça farklı oranda kolza içeren tüm numunelerin mekanik özelliklerinde iyileşme gözlenmiştir.

\section{MATERYAL VE METOT}

$\mathrm{Bu}$ çalışmada matris malzemesi olarak önemli bir ticari termoplastik olan polipropilen malzemesi kullanılmıştır. PETOPLEN EH102 kodlu polipropilen malzemesi PETKIM (Türkiye) şirketinden temin edilmiştir. Takviye elemanı olarak ise ögütülerek küçük parçalar haline getirilmiş kurutulmuş kolza bitkisi kullanılmıştır. Güneş 1şı̆̆ında iki hafta boyunca kurutulan kolza bitkisi daha sonra ögütülmüştür. Ögütülen kolza bitksinin boyutlarının birbirine yakın olması için önce 1 mm'lik elekten daha sonra $0.6 \mathrm{~mm}$ elekten geçirilmiştir ve elekte kalan malzemeler kullanılmıştır. Matris malzemesine ağırlıkça \%5, $\% 10$ ve $\% 20$ oranlarında kolza takviye edilerek farklı oranlara sahip karışımlar elde edilmiştir. Malzemelerin öncelikle eriyik akış indeksleri (MFI) belirlenmiştir. MFI testleri Munzur Üniversitesi Makine Mühendisliği Bölümü laboratuvarında bulunan "JPT EQUIPMANT marka XRL-400A model" MFI eriyik akış cihazı kullanılarak ASTM D1238 standartlarına uygun olarak gerçekleştirilmiştir. $\mathrm{Bu}$ standartlar çerçevesinde polipropilen için 230/2.16 değerleri yani $2.16 \mathrm{~kg}$ ağırlık ve $230{ }^{\circ} \mathrm{C}$ sicaklık kullanılarak deneyler gerçekleştirilmiştir. Tablo 1'de farklı oranlardaki kolza takviyeli polipropilen kompozit malzemesine ait eriyik akış indeksleri verilmiştir. Tablodan görüleceği üzere kolza katkısının artışı ile eriyik akış indeksinde düşüş meydana gelmiştir. Saf polipropilen malzemesinin eriyik akış indeksi $10.67 \mathrm{gr} / 10$ dakika iken bu değer \%20 kolza takviyeli polipropilen malzemesinde $6.71 \mathrm{gr} / 10$ dakika olarak ölçülmüştür. Malzemenin eriyik akış indeks değerleri ile matrise eklenecek maksimum takviye miktarı hakkında bilgi elde edilmiştir. Ağırlıkça \%20 kolza takviyesinin üzerindeki malzemelerde eriyik akış indeksi oldukça düşmektedir. $\mathrm{Bu}$ nedenle ağırlıkça daha yüksek takviye malzemesine sahip kompozit malzemeler üretilmemiştir. Ayrıca MFI testi ile ekstrüzyon ve enjeksiyon makinelerinde kullanılacak parametreler hakkında, özellikle sıcaklık ile ilgili ön bilgiler belirlemiştir. Eriyik akış indeksleri belirlendikten sonra bu karışımlar önce bir mikserde mekanik olarak karıştırılmış, ardından homojen bir karışım elde etmek için tek vidalı bir ekstrüzyon makinesine dökülerek plastik şerit elde edilmiştir. $\mathrm{Bu}$ homojenleştirme işlemi için 150 ila $170{ }^{\circ} \mathrm{C}$ 'de farklı 
sıcaklıklara sahip üç bölgeli ve bir kalıp 1sıtmalı ekstrüzyon kullanılmıştır. Ekstrüder çıkışında $4 \mathrm{~mm}$ çapındaki silindirik kesitten akan erimiş şerit halindeki karışım soğutma havuzuna daldırıldıktan hemen sonra bir konveyör bant vasitasıyla kırıcıya gönderilmiştir. Malzeme kırıcıdan geçirilerek 3 ila 5 mm boyutlarında granüller elde edilmiştir. Şekil 1'de saf ve farkl1 oranlarda kolza takviyeli polipropilen granülleri verilmiştir. Daha sonra bu granüller plastik enjeksiyon makinasına (EKİN 100 Ton) dökülerek Şekil 2'de boyutları verilen standart test numuneleri üretilmiştir.

Tablo 1. Farkl miktarda kolza malzemesi takviyeli PP Kompozit malzemesine ait eriyik akış indeksi

\begin{tabular}{|c|c|c|c|c|}
\hline & Saf PP & PP+\%5Kolza & PP+\%10Kolza & PP+\%20Kolza \\
\hline $\begin{array}{c}\text { MFI } \\
\text { (gr/10dak.) }\end{array}$ & 10.67 & 9.48 & 7.97 & 6.71 \\
\hline
\end{tabular}
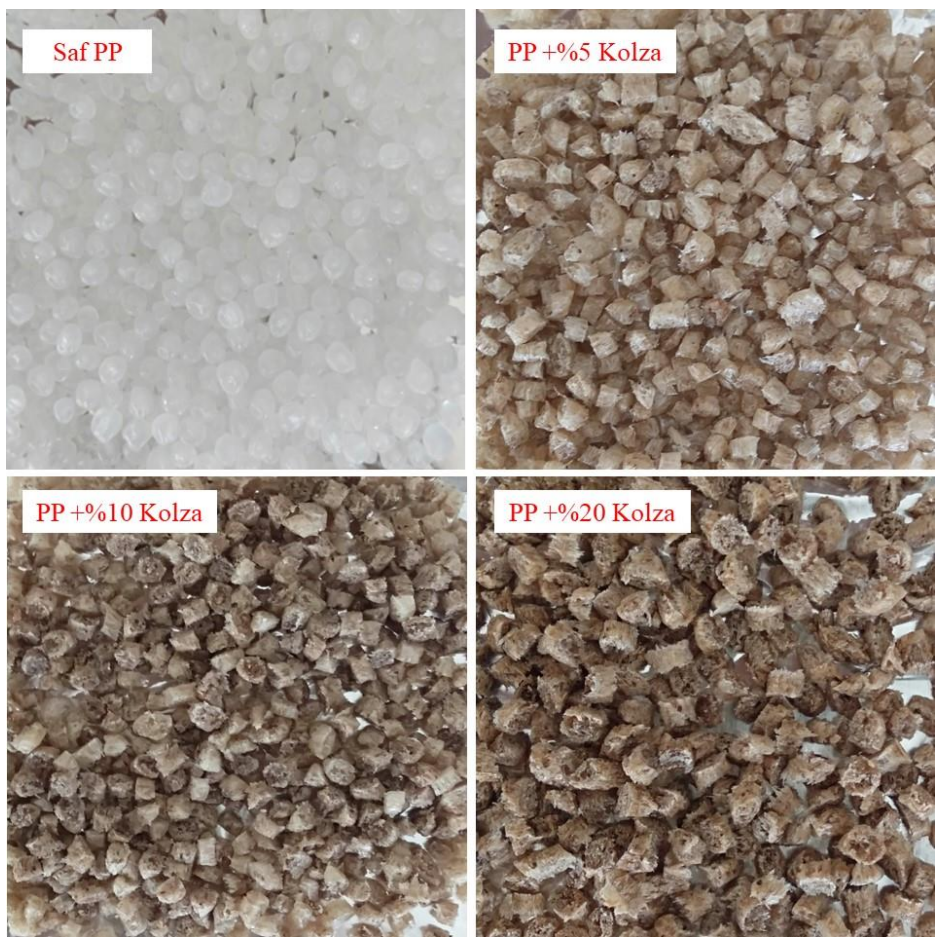

Şekil 1. Farklı oranlarda kolza takviyeli PP granüller
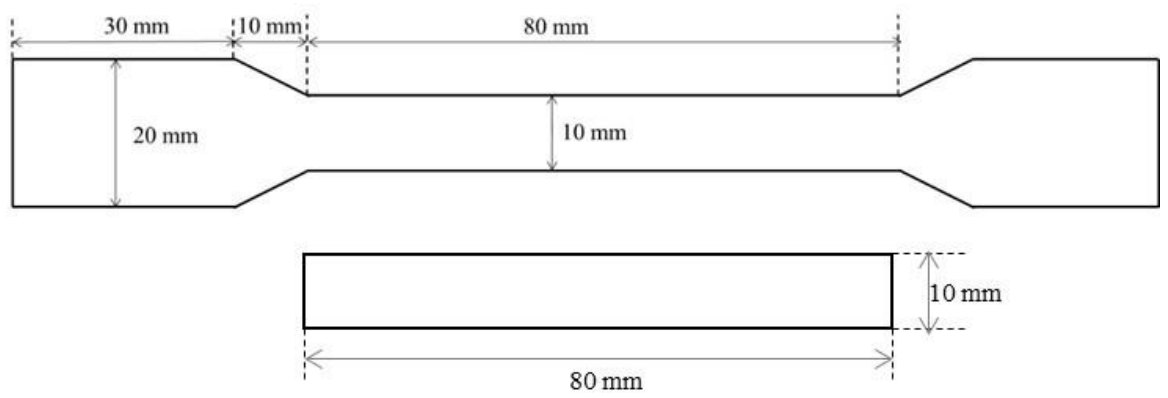

Şekil 2. Standart çekme ve üç-nokta eğilme test numunelerinin şematik olarak gösterimi 
Gama 1şıması etkisinin incelenmesi için, üretilen test numuneleri Türkiye Atom Enerjisi Kurumu'nda (TAEK) 24 saat boyunca 45 kGry gama 1şımasına maruz bırakılmıştır. Polipropilen ve kolza takviyesi ile oluşturulan kompozitlerin mekanik özelliklerindeki değişimler hem takviye elamanının oranına hem de gama 1şımasının etkisine bağlı olarak incelenmiştir. $\mathrm{Bu}$ mekanik özellikler kapsamında gerçekleştirilen çekme ve üç nokta eğilme testleri Munzur Üniversitesi Makine Mühendisliği bölümünde bulunan ve $100 \mathrm{kN}$ yük kapasitesine sahip Shimadzu AG-IC test cihazında yapılmıştır. Şekil 3a' da çekme testi öncesi ve sonrasi test düzeneği ile çekme numunesi verilmiştir. Çekme testleri EN ISO 527 standardına uygun olarak $50 \mathrm{~mm} /$ dakika h1z altında gerçekleştirilmiştir. Üç nokta eğilme testleri ise EN ISO 178 test standardına göre yapılmış ve test hız1 $10 \mathrm{~mm} /$ dakika olarak seçilmiştir. Üç nokta eğilme düzeneği Şekil 3b'de gösterilmiştir. Burada destekler arası mesafe $64 \mathrm{~mm}$, destek çapları ise 10 mm'dir. Eğilme mukavemeti $\left(\sigma_{b}\right)$ Denklem 1 yardımı ile bulunmuştur.

$$
\sigma_{b}=\frac{3 F L}{2 b t^{2}}
$$

Burada F kuvvet, L destekler arası mesafe, b numune genişliği, $t$ ise numune kalınlığıdır.

$\mathrm{Bu}$ testler sonucunda malzemelerin çekme ve eğilme mukavemetleri elde edilmiştir. Malzemelerin Izod darbe mukavemetlerini belirlemek için, Dokuz Eylül Üniversitesi Makine Mühendisliği bölümünde bulunan Ceast Fractovis Plus test cihazı kullanılmıştır.

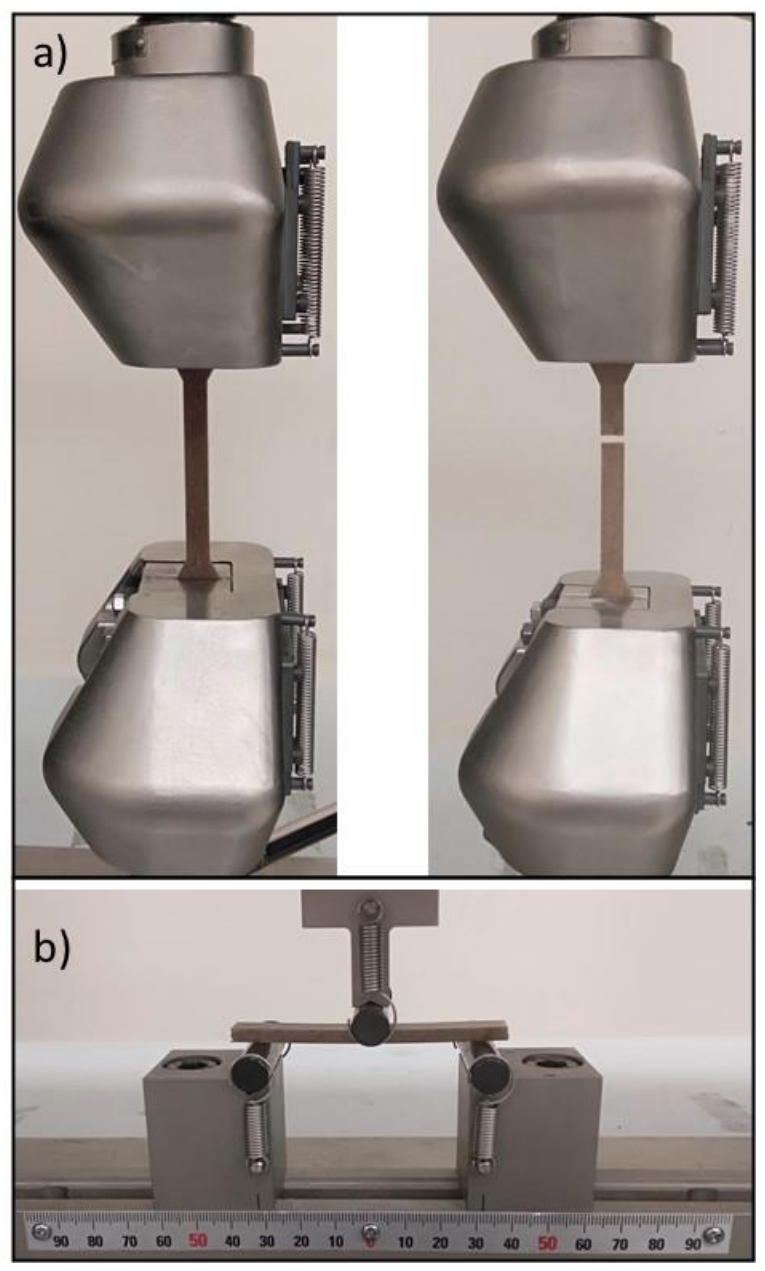

Şekil 3. Çekme testi ve eğilme testi düzenekleri 


\section{TARTIȘMA VE SONUÇ}

Ağırlıkça farklı oranlarda kolza takviyesine sahip polipropilen malzemelerinin ve aynı zamanda bu malzemelerin gama 1şımasına tabi tutulma durumlarına bağlı olarak elde edilen mekanik özelliklerine ait değişimler aşağıda sunulmuştur.

Saf polipropilen ve kolza takviyeli malzemelerin çekme testi sırasında elde edilen kuvvet-uzama eğrileri Şekil 4'de verilmiştir. Her bir malzeme için testler beş kez tekrarlanmıştır ve ortalama değerler alınarak standart sapmaları ile birlikte grafiklerde sunulmuştur. Şekilde görüldüğü üzere malzemelerin uzama değerlerinde dramatik bir düşüş meydana gelmiștir. Takviyeli malzeme saf malzemeye oranla daha gevrek bir duruma gelmiștir. Saf polipropilen malzemesinin ortlama uzama değeri $150 \mathrm{~mm}$ civarında iken bu değer \%20 kolza takviyeli propilen malzemesinde $6 \mathrm{~mm}$ 'ye kadar düşmüştür. Saf polipropilen malzemesi maksimum kuvvete ulaştıktan sonra bir miktar düşmüş ve daha sonra sabit kuvvet altında uzadıktan sonra kopmuştur. Bununla brlikte kolza takviyeli malzemelerde kuvvet maksimum değere ulaştıktan bir müddet sonra kopma meydana gelmiştir. çekme testi sonucunda hasara uğramış malzemelerin görüntüleri şekil 5'de verilmiştir. Yukarıda bahsedilen, katkı malzemesi ile birlikte malzemenin gevrek hale gelmesi şekilde açıkca görülmektedir.

Ağırlıç̧a farklı oranda kolza takviye edilen polipropilen matrisli kompozitlerin gama 1şıması öncesi ve sonrası çekme mukavemeti değerleri Şekil 6a'da verilmiştir. Şekilde görüleceği üzere, kolza takviyesi miktarının artışı ile, malzemenin çekme mukavemetinde düşüş eğilimi vardır. Saf polipropilen malzemesinin çekme mukavemeti 30.2 MPa iken \%5, \%10 ve \%20 kolza takviyeli polipropilen kompozit malzemelerinin çekme mukavemetleri sirasi ile $28.60 \mathrm{MPa}, 25.10 \mathrm{MPa}$ ve 23.70 MPa olarak belirlenmiştir. Gama 1şımasına maruz bırakılan aynı karışım oranlarına sahip numunelerin ise çekme mukavemetinde 1şıma etkisi ile artış meydana gelmiştir. Saf polipropilen malzemesinin çekme mukavemeti $31.80 \mathrm{MPa}$ olarak ölçülmüş, bu da yaklaşık \%5 artışa denk gelmektedir. Bununla birlikte, $\% 5, \% 10$ ve $\% 20$ kolza takviyeli polipropilen kompozit numunelerin çekme mukavemetleri gama 1şıması sonrası sırasıyla 30.60 $\mathrm{MPa}, 28.20 \mathrm{MPa}$ ve $26.70 \mathrm{MPa}$ olmuştur. Gama 1şıması etkisi ile $\% 5$ kolza takviyeli malzemenin çekme mukavemeti $\% 7$ oranında artarken, $\% 10$ ve \%20 kolza takviyeli malzemelerin çekme mukavemetinde ise yaklaşık \%12 oranında bir artış meydana gelmiştir. Çekme mukavemetindeki bu düşüş benzer şekilde, Yetkin ve Çolak (2020) tarafinda sunulan grafit katk1lı polipropilen kompozit malzede görülmüştür. $\mathrm{Bu}$ düşüşün sebebi, katk1 malzemesi ile polimer matris arasında oluşan zayıf arayüzey yapışması olabileceğini sunmuşlardır. Ayrıca, kolza katkı malzemesnin heterojen dağılması ve kolza malzemesinin mekanik özelliklerinin polipropilen malzemesinden düşük olma olasılığıda bu düşüşe sebep olan etkenler arasındadır. .

Şekil 6b'de ağırlıkça farklı oranlarda kolza miktarına sahip numunelere ait üç nokta eğilme mukavemetlerinin değişimi verilmiştir. Çekme mukavemetinin aksine, eğilme mukavemetinde $\% 5$ kolza takviyeli malzemede bir miktar düşüş gözlenmiş ancak \%10 ve \%20 kolza takviyeli malzelerde eğilme mukavemeti yükselmiştir. Saf polipropilen malzemesinin eğilme mukavemeti 43.10 MPa iken, \%5 kolza miktarına sahip malzemenin eğilme mukavemeti bir miktar azalarak $42.70 \mathrm{MPa}$ olmuştur. Bununla birlikte, kolza miktarı $\% 10$ ve $\% 20$ olan malzemelerin eğilme mukavemeti artarak sirasiyla $43.50 \mathrm{MPa}$ ve $44.20 \mathrm{MPa}$ olarak ölçülmüştür. Ancak şekilde de açıkça görüleceği üzere standart sapma değerleride yükselmiştir. Kolza malzemesinin homojen bir şekilde dağılmaması ve arayüzey yapışmasının düşük olması buna neden olarak gösterilebilir. Çekme mukavemetine benzer şekilde gama ışıması ile tüm numunelerin eğilme mukavemetleri aynı malzemelere göre yükselmiştir. Özellikle, \%10 kolza takviyeli numunelerin eğilme mukavemeti \%11 artarak $48.50 \mathrm{MPa}$ olarak belirlenmiştir. Gama 1şıması sonrası, Saf PP, ağırlıça \%5 ve \%20 kolza katkılı numunelerin eğilme mukavemetleri sirasiyla $46.10 \mathrm{MPa}, 46.30$ $\mathrm{MPa}$ ve $47.20 \mathrm{MPa}$ olarak ölçülmüştür. Ayrıca şekilde de görüldüğü üzere, malzemelerin standart sapmalarında da gama 1şıması sonrası düşüş meydana gelmiştir. 
Research article/Araştırma makalesi

DOI: 10.29132/ijpas.996361
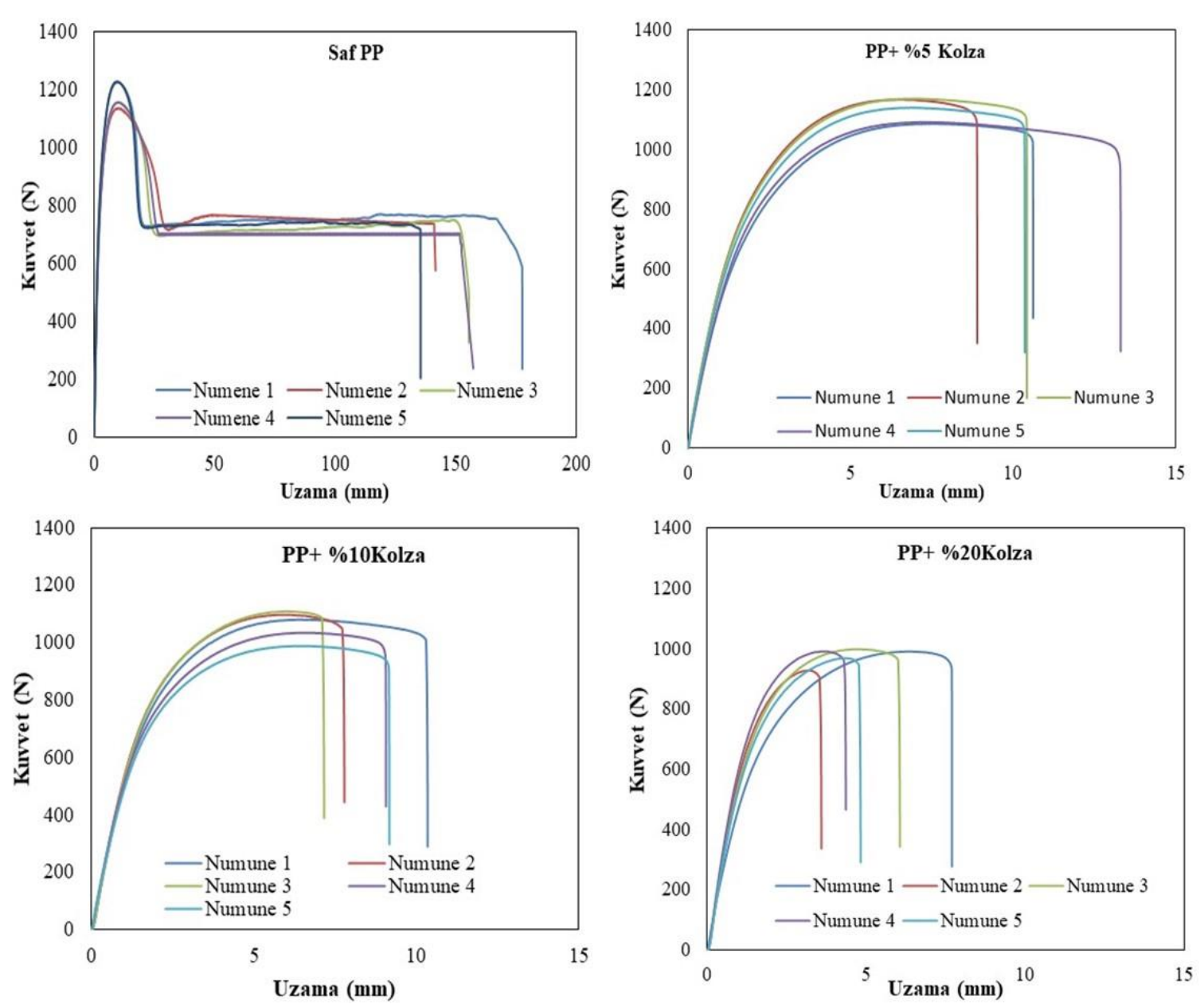

Şekil 4. Çekme testi sonucunda elde edilen kuvvet-uzama eğrileri
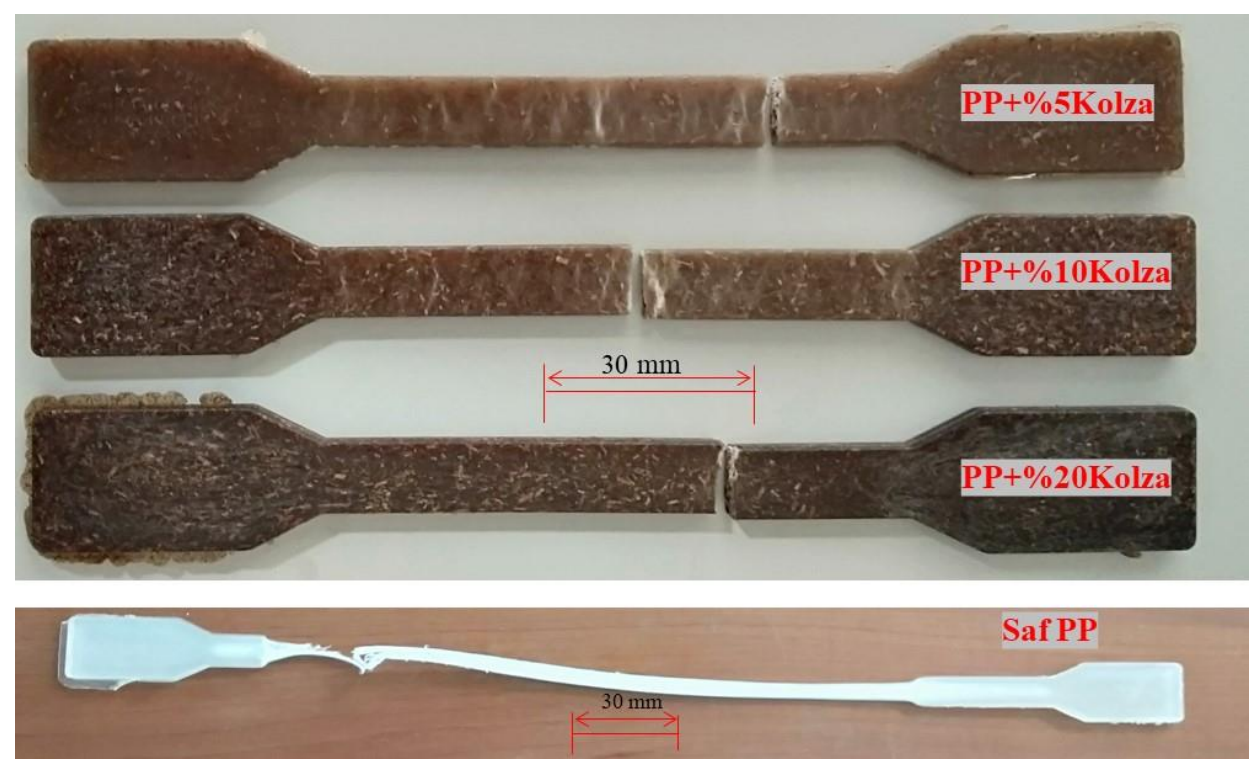

Şekil 5. Çekme testi sonucunda malzemelerde oluşan hasar görüntüleri 

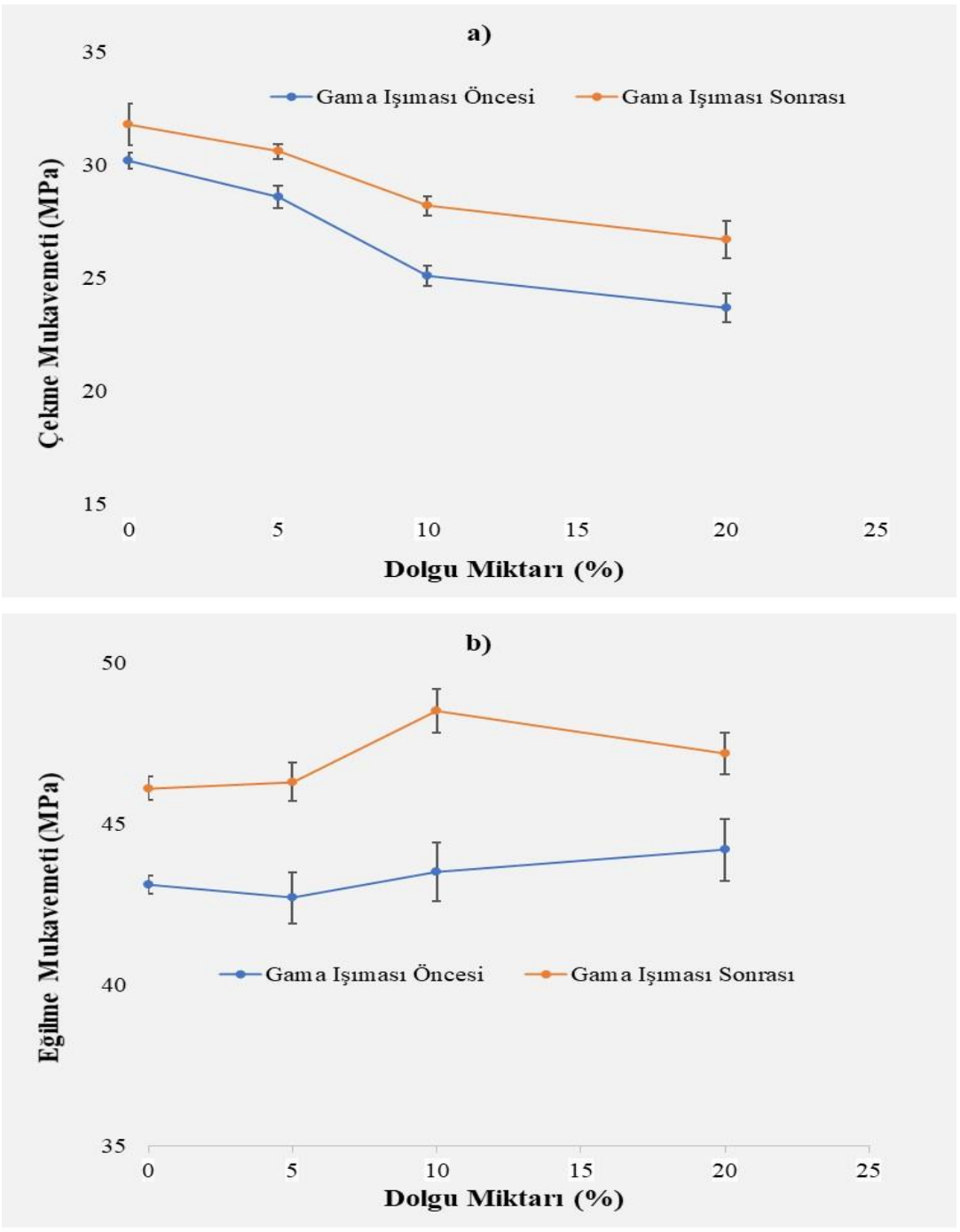

15

c)

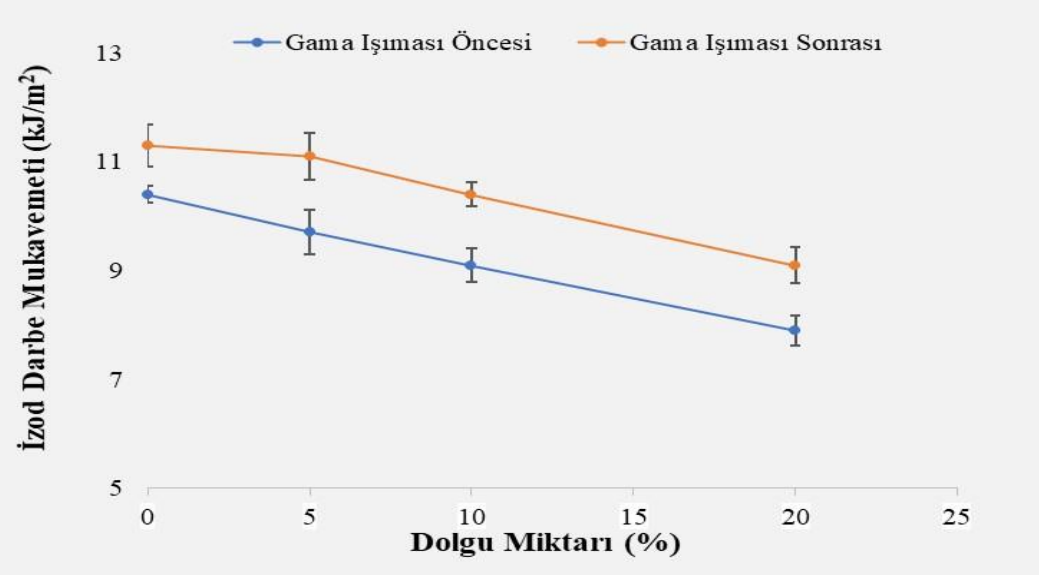

Şekil 6. Gama ışıması öncesi ve sonrası kolza takviyeli PP numunelerinin a) çekme b) eğilme c) izod darbe mukavemetindeki değişim 

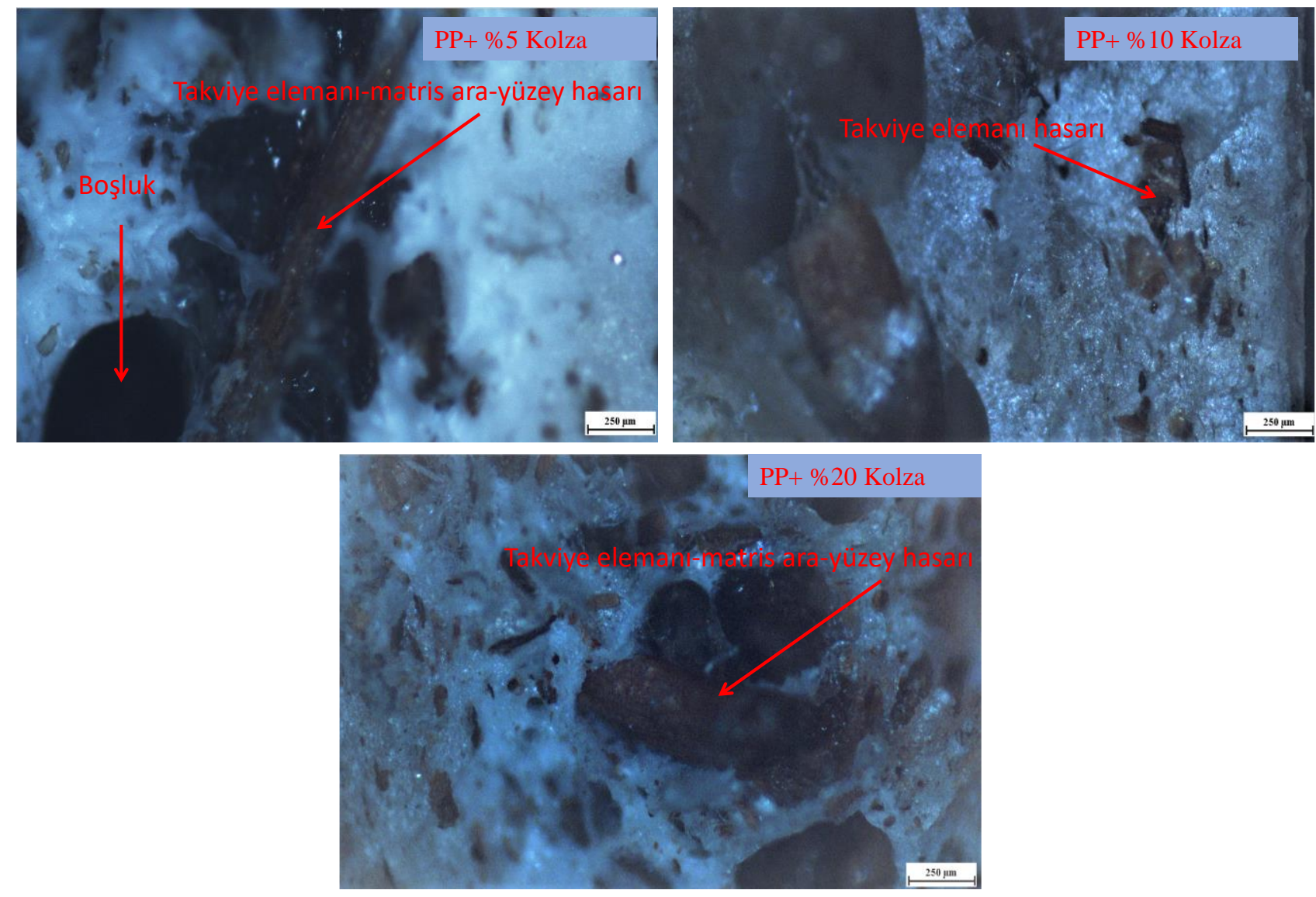

Şekil 7. Hasara uğramış malzemelerin kesitlerinin mikroskobik görüntüleri

Şekil 6c'de ise izod darbe mukavemetinin kolza takviyesi miktarı ve gama ışıması ile değişimi gösteren grafikler verilmiştir. Şekilde açıkça görüleceği üzere takviye malzemesinin artışı ile izod mukavemetinde azalış meydana gelmiştir. Saf polipropilen malzemesinin izod darbe mukavemeti $10.40 \mathrm{~kJ} / \mathrm{m}^{2}$ iken bu değer ağırlıkça $\% 5, \% 10$ ve $\% 20$ kolza takviyeli malzemeler için sırasıyla $9.7 \mathrm{~kJ} / \mathrm{m} 2$; $9.1 \mathrm{~kJ} / \mathrm{m}^{2}$ ve $7.9 \mathrm{~kJ} / \mathrm{m}^{2}$ olarak ölçülmüştür. Gama 1şımasına maruz kalan numunelerin izod darbe mukavemetinde artış meydana gelmiştir. Saf PP ve ağırlıkça \%5, \%10 ve \%20 kolza takviyeli PP numunelerin izod darbe mukavemetleri gama ıșıması sonras1 sirasiyla $11.30 \mathrm{~kJ} / \mathrm{m}^{2}, 11.10 \mathrm{~kJ} / \mathrm{m}^{2}, 10.40$ $\mathrm{kJ} / \mathrm{m}^{2}$ ve $9.10 \mathrm{~kJ} / \mathrm{m}^{2}$ olarak ölçülmüştür. Gama 1şıması sonrası izod darbe mukavemetinde saf polipropilen de yaklaşı1k \%8.6 artış olurken, kolza takviyeli malzemelerde gama 1şıması sonrası izod darbe mukavemetinde \%15'e yakın artış meydana geldiği gözlemlenmiştir.
Çekme testi sonucunda hasara uğramış kolza takviyeli polipropilen malzemelerinin kestlerinin mikroskobik görüntüleri NIKON marka ECLIPSE MA100 optik mikroskobu kullanılarak Şekil 7'de verilmiştir. Şekildede görüleceği üzere, takviye elemanı hasarı ve takviye elemanı ile matrtis arasındaki ara-yüzey hasarları ana hasar modlarıdır. Ayrıca homojen bir dağılım olmadığından dolayı meydana gelen boşluklarda mevcuttur. $\mathrm{Bu}$ boşluklarda malzemenin mukavemetinde düşüşe neden olacaktır.

\section{DEĞERLENDİRME}

$\mathrm{Bu}$ çalışmada ağırlıkça farklı oranlarda kolza takviyeli polipropilenin mekanik özelliklerindeki değişimler hem kolza oranına bağlı olarak hem de gama 1şıması etkisine bağlı olarak araştırılmıştır. Polipropilen içerisinde ağırlıkça artan kolza miktarına bağlı olarak numunelerin çekme ve izod darbe dayanımlarının azaldığı tespit edildi. Bununla birlikte üç nokta eğilme testleri neticesinde ise 
polipropilen içerisinde artan kolza miktarı ile numunelerin eğilme mukavemetinde artış görülmüştür. Ayrıca Gama 1şımasına maruz bırakılan malzemelerin mekanik özellikleri iyileşsede çekme ve izod darbe mukavemetlerinin yine kolza takviyesinin artması ile düştüğü gözlenmiştir. Bu düşüşün önlemek için kolza malzemesine alkali iyileştirme gibi yüzey iyileştirme yöntemleri uygulanarak polipropilen ile kolza arasındaki arayüzey yapıșma mukavemeti arttırılabilir. Ayrıca çift vidali ekstruder kullanılarak daha homejen bir yap1 elde edilebilir. Böylece mekanik özellikler iyileştirilebilir.

\section{ÇIKAR ÇATIŞMASI BEYANI}

Yazarlar bu makale ile ilgili herhangi bir çıkar çatışması bildirmemektedir.

\section{ARAŞTIRMA VE YAYIN ETÍĞİ BEYANI}

Yazar/Yazarlar bu çalışmanın araştırma ve yayın etiğine uygun olduğunu beyan eder.

\section{KAYNAKLAR}

Agrebi F., Hammami H., Asim M., Jawaid M., Kallel A. (2020). Impact of silane treatment on the dielectric properties of pineapple leaf/kenaf fiber reinforced phenolic composites. Journal of Composite Materials, 54 (7), 937-946.

Alothman O.Y., Alrashed M.M., Anis A., Naveen J., Jawaid M. (2020). Characterization of date palm fiber-reinforced different polypropylene matrices. Polymers, 12 (3), 597.

Aruchamy K., Subramani S.P., Palaniappan S.K., Sethuraman , Kaliyannan G.V. (2020). Study on mechanical characteristics of woven cotton/bamboo hybrid reinforced composite laminates. Journal of Materials Research and Technology, 9 (1), 718-726.

Dogan A., Arman Y. (2018). The effect of hygrothermal aging on the glass and carbon reinforced epoxy composites for different stacking sequences. Mechanics, 24 (1), 19-25.

Fiore V., Di Bella G., Valenza A. (2015). The effect of alkaline treatment on mechanical properties of kenaf fibers and their epoxy composites. Composites Part $B$ : Engineering, 68, 14-21.

Girones J., Méndez J.A., Boufi S., Vilaseca F., Mutjé P. (2007). Effect of silane coupling agents on the properties of pine fibers/polypropylene composites. Journal of Applied Polymer Science, 103 (6), 37063717.
Jariwala H., Jain P. (2019). A review on mechanical behavior of natural fiber reinforced polymer composites and its applications. Journal of Reinforced Plastics and Composites, 38 (10), 441453.

Kandas, H., Özdemir O. (2021). Çam ve Meşe Palamudu Tozu Takviyeli Kompozitlerin Mekanik Özelliklerinin İncelenmesi. Dokuz Eylül Üniversitesi Mühendislik Fakültesi Fen ve Mühendislik Dergisi, 23 (67), 147-155.

Kenned J.J., Sankaranarayanasamy K., Binoj J.S., Chelliah S.K. (2020). Thermo-mechanical and morphological characterization of needle punched non-woven banana fiber reinforced polymer composites. Composites Science and Technology, 185, 107890.

Kismet Y., Dogan A. (2021). Characterization of the mechanical and thermal properties of rape short natural-fiber reinforced thermoplastic composites. Iran Polym Journal https://doi.org/10.1007/s13726-021-00988-9

Koohestani B., Darban A.K., Mokhtari P., Yilmaz E. \& Darezereshki, E. (2019). Comparison of different natural fiber treatments: a literature review. International Journal of Environmental Science and Technology, 16(1), 629-642.

Madenci E., Ozutok A. (2020). Variational approximate for high order bending analysis of laminated composite plates. Structural Engineering and Mechanics, 73(1), 97-108.

Madenci E., Özkılıç Y.O., Gemi L. (2020). Theoretical investigation on static analysis of pultruded GFRP composite beams. Academic Platform Journal of Engineering and Science, 8(3), 483-490.

Madenci E., Özkılıç Y.O., Gemi, L. (2020). Experimental and theoretical investigation on flexure performance of pultruded GFRP composite beams with damage analyses. Composite Structures, 242, 112162.

Ovalı S., Sancak E., (2020). Investigation of mechanical properties of jute fiber reinforced low density polyethylene composites. Journal of Natural Fibers, 1-18.

Özkılıç Y.O., Madenci E.,Gemi L. (2020). Tensile and compressive behaviors of the pultruded GFRP lamina. Turkish Journal of Engineering, 4(4), 169175.

Simimol A.S., Sebastian S., Ravindranath D.A., Jacob A. (2020). Enhancement of Physical, Mechanicaland Morphological Properties of Coir by Mercerization and Acetylation. International Journal of Innovative Science and Research Technology, 5, 530-535. 
Singh Y., Singh J., Sharma S., Lam T.D., Nguyen D.N. (2020). Fabrication and characterization of coir/carbon-fiber reinforced epoxy based hybrid composite for helmet shells and sports-good applications: influence of fiber surface modifications on the mechanical, thermal and morphological properties. Journal of Materials Research and Technology, 9 (6), 15593-15603.

Sreekala M.S., Kumaran M.G., Joseph S., Jacob M., Thomas S. (2000). Oil palm fibre reinforced phenol formaldehyde composites: influence of fibre surface modifications on the mechanical performance. Applied Composite Materials, 7(5), 295-329.

Vigneshwaran S., Sundarakannan R., John K.M., Johnson R.D.J., Prasath K.A., Ajith S., Arumugaprabu V., Uthayakumar M. (2020). Recent advancement in the natural fiber polymer composites: A comprehensive review. Journal of Cleaner Production, 227, 124109.

Wang A., Wang X., Xian G. (2020). Mechanical, lowvelocity impact, and hydrothermal aging properties of flax/carbon hybrid composite plates. Polymer Testing, 90, 106759.

Widnyana A., Rian G., Surata W., Nindhia T.G.D. (2020). Tensile Properties of coconut Coir single fiber with alkali treatment and reinforcement effect on unsaturated polyester polymer. Materials Today: Proceedings, 22, 300-305.

Yetkin S., Çolak M. (2020). Grafit katkılı polipropilen kompozitlerin mekanik ve tribolojik özelliklerinin incelenmesi. El-Cezeri Journal of Science and Engineering, 7(2), 649-658.

Zaman H.U., Khan R.A. (2021). Acetylation used for natural fiber/polymer composites. Journal of Thermoplastic Composite Materials, 34 (1), 3-23. 